\title{
Effect of Delta Current and Delta Current Frequency on tensile properties and microstructure of Gas Tungsten Constricted Arc (GTCA) welded Inconel 718 sheets
}

https://doi.org/10.1515/jmbm-2019-0020

Received Nov 01, 2019; accepted Dec 07, 2019

\section{Introduction}

Inconel 718 is a Ni-Cr-Fe based alloy containing $\mathrm{Nb}, \mathrm{Mo}$, $\mathrm{Ti}$ and $\mathrm{Al}$ as principal strengthening elements [1]. It is strengthened by gamma prime $\gamma^{\prime}\left[\mathrm{Ni}_{3}(\mathrm{Al}, \mathrm{Ti})\right]$ and gamma double prime precipitates $\gamma^{\prime \prime}\left(\mathrm{Ni}_{3} \mathrm{Nb}\right)$ [2]. It possesses high strength, excellent creep and stress rupture properties, good corrosion and oxidation resistance [3]. It possesses excellent resistance to strain age cracking due to its sluggish precipitation behavior of gamma double prime precipitates [4]. It is used in rocket combustor, gas turbine engines for casing, discs and blades, in high temperature system of cryogenic rocket engines etc [5, 6]. It finds major applications in critically stressed components at a high temperature up to $650^{\circ} \mathrm{C}$ [7].

Gas tungsten arc welding (GTAW) process is widely used for joining Inconel 718 alloy for the fabrication and service repair of the components as it is economical, shop friendly and give clean and precise welds. The main constraint in joining of Inconel 718 alloy by GTAW process is the segregation of alloying elements and laves phase formation in weld metal region due to the high heat input as the arc is wider and heat intensity of the arc is less. The formation of laves phase has deleterious effects on the weld mechanical properties. Radhakrishna et al. [8] found that faster cooling rate in EBW reduces the segregation and laves phase formation in Inconel 718 welds significantly. Hence the joining techniques which increase the cooling rate and refine the dendrite structure of fusion zone, can control the problem of segregation and improve the weld mechanical properties. Ram et al. [9] employed current pulsing technique in GTAW process and achieved improved tensile properties due to the refinement in fusion zone microstructure. Sivaprasad et al. [10] observed finer and discrete laves phase formation in Inconel 718 welds due to the refinement in fusion zone by magnetic arc oscillation technique in GTAW process; thereby achieved im-

\footnotetext{
${ }^{\star}$ Corresponding Author: Visvalingam Balasubramanian: Centre for Materials Joining and Research (CEMAJOR), Department of Manufacturing Engineering, Annamalai University, Annamalai Nagar-608002, Tamilnadu; Email: visvabalu@yahoo.com Tushar Sonar, Sudersanan Malarvizhi: Centre for Materials Joining and Research (CEMAJOR), Department of Manufacturing Engineering, Annamalai University, Annamalai Nagar-608002, Tamilnadu

Thiruvenkatam Venkateswaran, Dhenuvakonda Sivakumar: Vikram Sarabhai Space Centre (VSSC), ISRO, Thiruvananthapuram 695022, Kerala
}

əopen Access. @ 2019 T. Sonar et al., published by De Gruyter. License 
Table 1: Chemical composition (\% by weight) of base metal

\begin{tabular}{cccccccccccccc}
\hline $\mathbf{N i}$ & $\mathrm{Cr}$ & $\mathrm{Fe}$ & $\mathrm{Co}$ & $\mathrm{Mo}$ & $\mathrm{Nb}$ & $\mathrm{Ti}$ & $\mathrm{Al}$ & $\mathrm{C}$ & $\mathrm{Mn}$ & $\mathrm{Si}$ & $\mathrm{B}$ & $\mathrm{Cu}$ & $\mathrm{S}$ \\
\hline 55.5 & 17.7 & 21.8 & 0.04 & 3 & 4.96 & 0.93 & 0.44 & 0.43 & 0.017 & 0.06 & 0.003 & 0.001 & 0.004 \\
\hline
\end{tabular}

Table 2: Mechanical properties of base metal

\begin{tabular}{cccc}
\hline $\begin{array}{c}\text { Tensile strength } \\
(\mathrm{MPa})\end{array}$ & $\begin{array}{c}\mathbf{0 . 2 \%} \text { Offset yield strength } \\
(\mathrm{MPa})\end{array}$ & Elongation (\%) in $\mathbf{5 0 ~} \mathbf{~ m m}$ gauge length & $\begin{array}{c}\text { Micro hardness } \\
\left(\mathrm{HV}_{\mathbf{0 . 5}}\right)\end{array}$ \\
\hline 870 & 580 & 38 & 292 \\
\hline
\end{tabular}

proved tensile properties in welded joints. Manikandan et al. [11] used liquid nitrogen cooling in GTA welding of Inconel 718 alloy to enhance the cooling rate and reduce the segregation of $\mathrm{Nb}$. In this investigation, a newly developed gas tungsten constricted arc (GTCA) welding process is used to join Inconel 718 alloy to refine the dendritic structure of fusion zone. GTCAW is the advanced variant of GTAW process which involves the use of magnetic arc constriction produced by Delta Current pulsing at a very high frequency up to $20 \mathrm{kHz}$.

The research on welding of Inconel 718 alloy, so far, is mainly focussed on the gas tungsten arc welding (GTAW) [12-14], electron beam welding (EBW) $[15,16]$ and laser beam welding (LBW) $[17,18]$. Researchers reported the use of current pulsing [19-21] and magnetic arc oscillation technique [22-24] to reduce the heat input and refine the fusion zone microstructure of Inconel 718 welds. However, the published literature on the use of gas tungsten constricted arc (GTCA) welding of Inconel 718 alloy is deficient. Delta Current and Delta Current Frequency are the main controlling parameters for the magnetic arc constriction in GTCAW. So, the main objective of this research work is to investigate the effect of Delta Current (DC) and Delta Current Frequency (DCF) on the tensile properties and microstructure of Inconel 718 alloy joints.

\section{Experimental methodology}

The rolled $2 \mathrm{~mm}$ thick sheets of Inconel 718 alloy in $980^{\circ} \mathrm{C}$ solution treated condition was used for the present investigation. Table 1 shows the chemical composition of base metal. The mechanical properties of base metal are presented in Table 2. The sheets were cut into required size for the preparation of square butt joint as shown in Figure 1. Gas tungsten constricted arc (GTCA) welding machine (Make \& Model: VBC, UK; InterPulse IE175i) was used to fabricate the weld joints to produce single pass au-

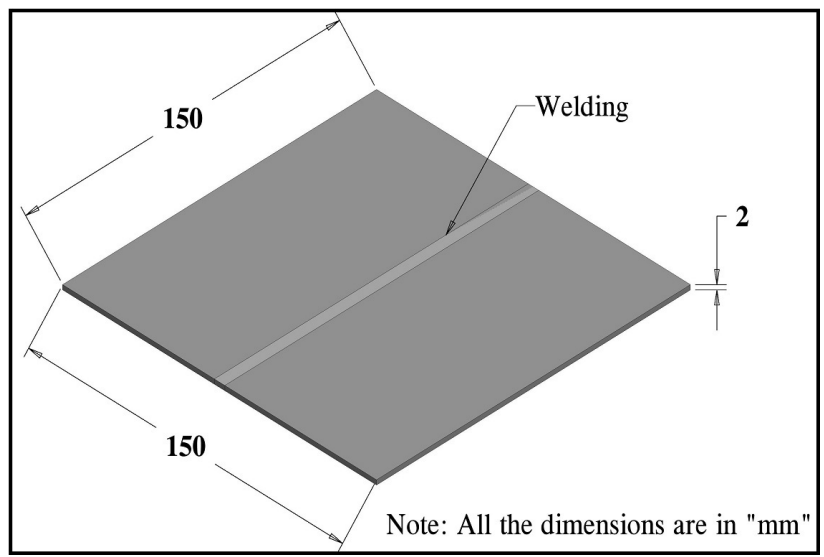

Figure 1: Joint configuration used in this investigation

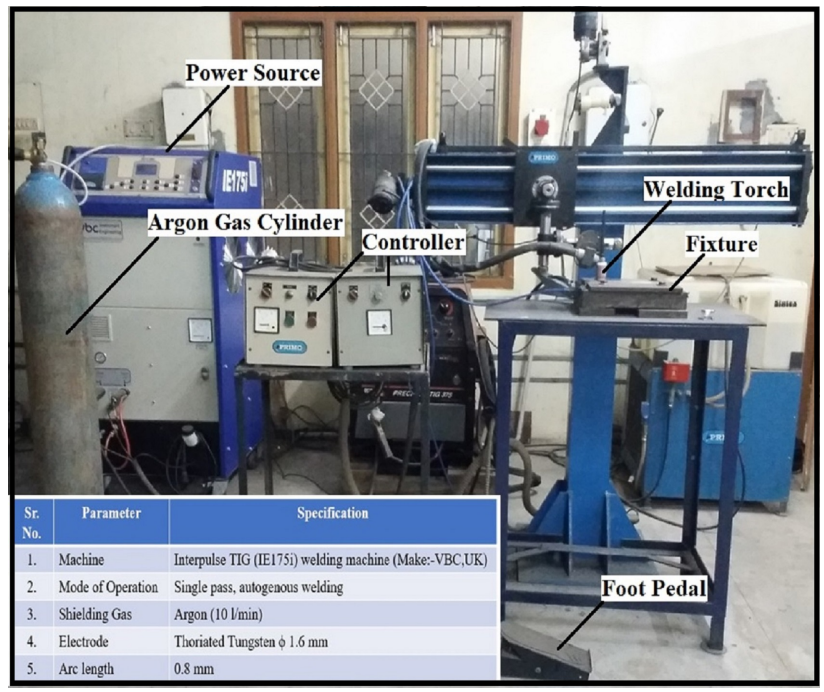

Figure 2: GTCA welding machine set up

togenous welds. Figure 2 shows the setup of GTCA welding machine used in the present investigation. The delta straight arc mode was selected for deeper penetration in welding. One factor at a time approach was selected to design the experiment. The welding parameters used for the 
Table 3: Process parameters for GTCA welding of Inconel 718 alloy

\begin{tabular}{ccccccc}
\hline & $\begin{array}{c}\text { Main current } \\
(\mathbf{A})\end{array}$ & $\begin{array}{c}\text { Delta Current } \\
(\mathbf{A})\end{array}$ & $\begin{array}{c}\text { Delta Current } \\
\text { Frequency } \\
(\mathbf{k H z})\end{array}$ & $\begin{array}{c}\text { Welding } \\
\text { speed } \\
(\mathbf{m m} / \mathbf{m i n})\end{array}$ & $\begin{array}{c}\text { Voltage } \\
(\mathbf{V})\end{array}$ & $\begin{array}{c}\text { Heat input } \\
(\mathrm{J} / \mathbf{m m})\end{array}$ \\
\hline Delta Current & 65 & 40 & 12 & 60 & 9 & 472 \\
& 65 & 45 & 12 & 60 & 9 & 495 \\
& 65 & 50 & 12 & 60 & 9 & 517 \\
& 65 & 55 & 12 & 60 & 9 & 540 \\
\hline Delta Current & 65 & 60 & 12 & 60 & 9 & 562 \\
frequency & 65 & 50 & 4 & 60 & 9 & 518 \\
& 65 & 50 & 8 & 60 & 9 & 518 \\
& 65 & 50 & 12 & 60 & 9 & 518 \\
& 65 & 50 & 16 & 60 & 9 & 518 \\
& 65 & 50 & 20 & 60 & 9 & 518 \\
\hline
\end{tabular}

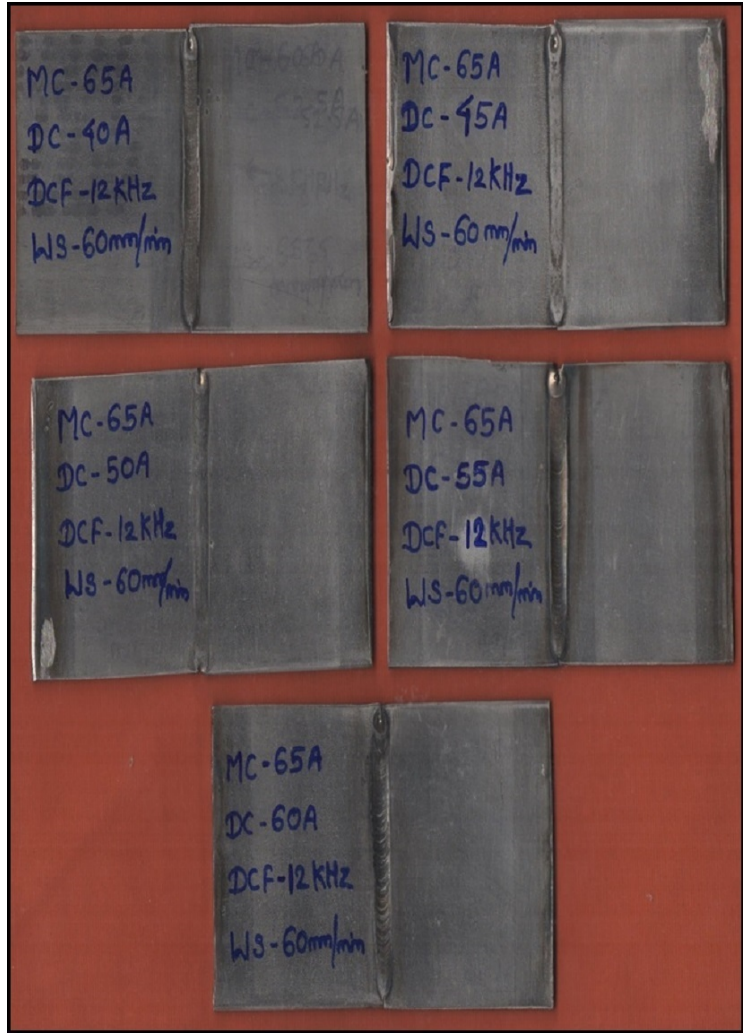

(a) Joints fabricated at various levels of Delta Current

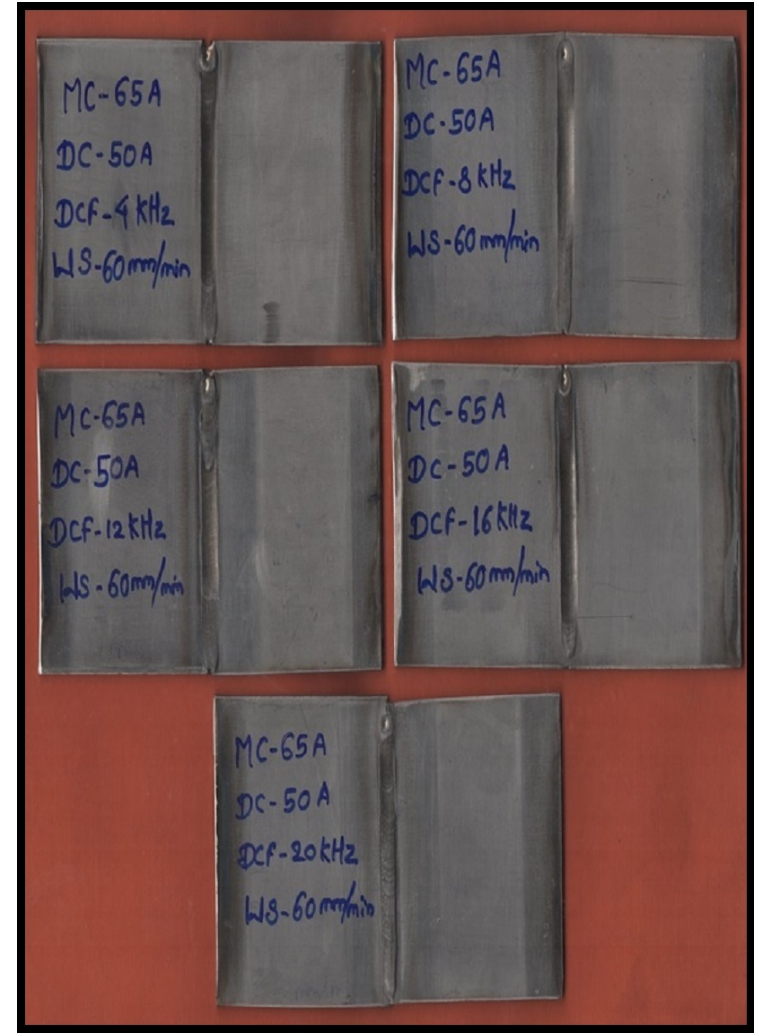

(b) Joints fabricated at various levels of Delta Current Frequency

Figure 3: Photograph of welded joints

fabrication of the joints are listed in Table 3. The photograph of the welded joints is shown in Figure 3.

Figure 4 shows the dimensions of the tensile specimens extracted from the welded joints. The tensile testing was carried out as per ASTM E8M-05 standard using a $50 \mathrm{kN}$ servo-controlled tensile testing machine (Make
\& Model: Tinius Olsen, Horsham, Pennsylvania; H50KL). The tensile specimens were subjected to a tensile loading at a cross head speed of $2 \mathrm{~mm} / \mathrm{min}$. The $0.2 \%$ offset method was used to calculate the yield strength from the engineering stress-strain curve of the tested specimen. The tensile elongation was measured at a gauge length of 50 


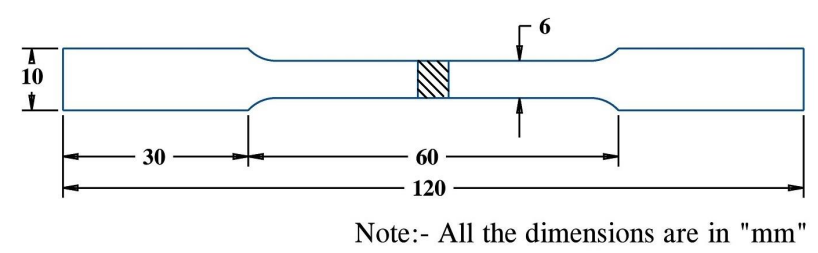

Figure 4: Dimensions of the transverse tensile specimen extracted from the welded joints

$\mathrm{mm}$. Three tensile specimens were tested and the average of three was reported as final property value. The tensile fracture surface was analysed by SEM.

Vickers microhardness was measured as per ASTM E384-17 standard on the mirror polished cross-sectional surface of the metallographic samples. The microhardness survey was carried out across the mid thickness region from the weld centre at an interval of $0.1 \mathrm{~mm}$. The microhardness was measured in the weld centre using a Vickers Microhardness testing machine (Make \& Model: SHIMADZU HMV-2T) at a testing load of $0.5 \mathrm{~kg}$ and $15 \mathrm{~s}$ dwell time. The average microhardness of $\mathrm{FZ}$ and $\mathrm{HAZ}$ was also recorded.

The microstructural analysis was performed at the cross section of the mirror polished metallographic samples etched by Kalling's reagent. The stereozoom microscope was used to record the macrostructure of the welded joints. Image J analyzer software was used to measure the weld bead geometry. The etched metallographic samples were then observed under an optical microscope (Make \& Model: MEJI, Japan; MIL-7100) and the microstructure was recorded at different magnifications.

\section{Calculation of heat input}

The heat input $(\mathrm{J} / \mathrm{mm})$ was calculated using the general formula

$$
H i=\frac{I_{a v g} \times V \times \eta}{S}
$$

where $I_{a v g}$ is the average of main current and Delta Current in amps, $V$ is the arc voltage in volts, $S$ is the welding speed in $\mathrm{mm} / \mathrm{min}$ and $\eta$ is the efficiency of the process in $\%$.

\section{Results}

\subsection{Macrostructure}

Tables 4 and 5 show the effect of DC and DCF on the macrostructure of the welded joints. All the joints were observed to be defect free. Complete penetration was obtained in all the joints. As DC increases, the weld bead geometry decreases from a lower level of $40 \mathrm{~A}$ to $50 \mathrm{~A}$. It is due to the increase in magnetic arc constriction which reduces the heat input and causes localized melting of the metal at the joint. Further increase in DC to a higher level of $60 \mathrm{~A}$ results in increase in weld bead geometry. It is due to the increase in heat input during welding owing to the constant welding speed resulting in more melting of metal at the joint. The joints welded above the DC of 50 A showed increase in concavity on the top surface. The increase in arc force and more melting of metal at the joint due to the higher heat input is responsible for the deeper concavity on the weld pool surface at a higher level of $60 \mathrm{~A}$.

The increase in DCF results in an increase in the weld bead geometry. But there are no significant changes in the weld bead size up to $12 \mathrm{kHz}$. However, it increases significantly at a higher level of DCF ( $20 \mathrm{kHz})$ as compared to the lower level $(4 \mathrm{kHz})$. The Fusion zone area is increased significantly by $13.38 \%$ at a higher level as compared to the lower level. The width of the weld bead and HAZ increases with an increase in DCF. It is attributed to the increase in average heat input during welding with increase in DCF. The joints welded at a $50 \mathrm{~A} \mathrm{DC}$ and $4 \mathrm{kHz}$ DCF showed better weld bead geometry. It shows that the weld bead geometry is sensitive to the change in the level of DC and DCF and necessitates the optimum selection to control the weld bead.

\subsection{Tensile properties}

The transverse tensile properties of the welded joints at different levels of DC and DCF are presented in Table 6 and 7 respectively. The tensile properties of all the joints are lower than the base metal. It is due to the difference in the microstructural characteristics of base metal and fusion zone. Figure 5 shows the photograph of tensile specimens after testing. All the joints welded at different levels of DC and DCF failed in the fusion zone only. It is attributed to the segregation of alloying elements resulting in the formation of hard and brittle laves phase in fusion zone which does not assist in plastic deformation [25-27]. Figure 6 represents the effect of DC on the tensile properties of welded joints. Increase in DC results in an increase in tensile and yield strength from a lower level of $40 \mathrm{~A}$ to mid-level of $50 \mathrm{~A}$. It is due to the increase in magnetic arc constriction which reduces the average heat input during welding. Further increase above 50 A results in a considerable decrease in the strength of the welded joints. Similar results were obtained for the tensile elongation of the welded joints. DC at a higher level of $60 \mathrm{~A}$ results in a 30\% 
Table 4: Effect of Delta Current on weld bead geometry

\begin{tabular}{|c|c|c|c|c|c|c|}
\hline $\begin{array}{l}\text { Delta } \\
\text { Current } \\
\text { (A) }\end{array}$ & Macrograph & $\begin{array}{l}\text { Bead } \\
\text { width } \\
(\mathrm{mm})\end{array}$ & $\begin{array}{l}\text { Bead } \\
\text { depth } \\
(\mathrm{mm})\end{array}$ & $\begin{array}{c}\text { Avg. HAZ } \\
\text { width } \\
(\mathrm{mm})\end{array}$ & $\begin{array}{c}\text { FZ area } \\
\left(\mathrm{mm}^{2}\right)\end{array}$ & Observations \\
\hline 40 & & 4.72 & 2.00 & 0.33 & 7.68 & Full penetration \\
\hline 45 & & 4.45 & 2.00 & 0.42 & 7.56 & Full penetration \\
\hline 50 & & 4.37 & 2.00 & 0.46 & 7.46 & Full penetration \\
\hline 55 & & 5.16 & 2.00 & 0.58 & 8.37 & Excess penetration \\
\hline 60 & & 4.91 & 2.00 & 0.62 & 8.27 & Excess penetration \\
\hline
\end{tabular}

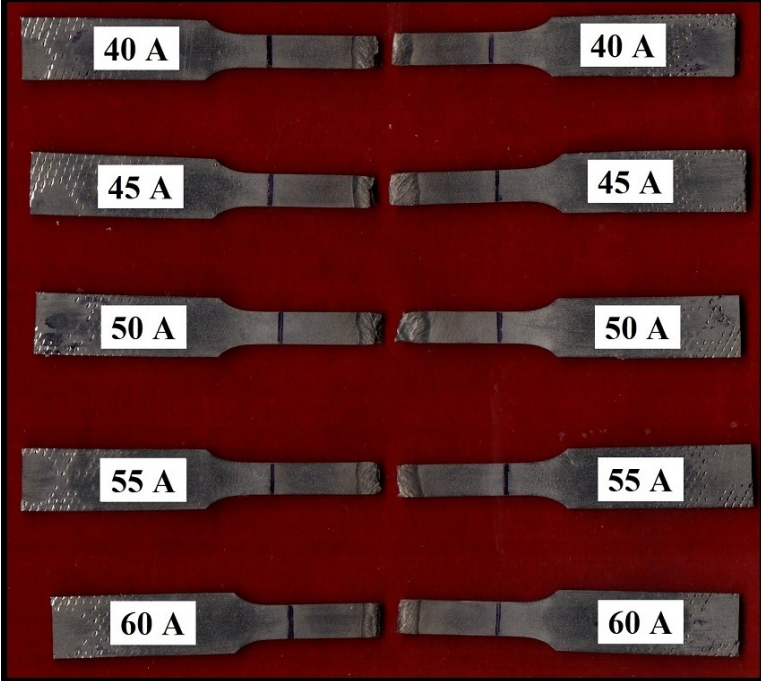

(a) Delta Current

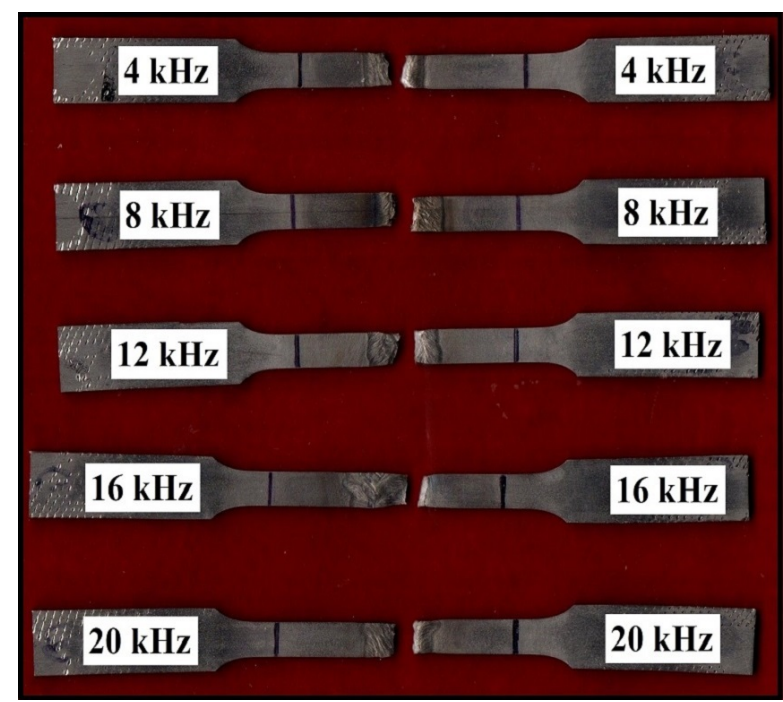

(b) Delta Current Frequency

Figure 5: Photograph of tensile specimens after testing 
Table 5: Effect of Delta Current Frequency on weld bead geometry

\begin{tabular}{|c|c|c|c|c|c|c|}
\hline $\begin{array}{l}\text { Delta Current } \\
\text { Frequency } \\
\text { (kHz) }\end{array}$ & Macrograph & $\begin{array}{l}\text { Bead } \\
\text { width } \\
(\mathrm{mm})\end{array}$ & $\begin{array}{l}\text { Bead } \\
\text { depth } \\
(\mathrm{mm})\end{array}$ & $\begin{array}{l}\text { Avg. HAZ } \\
\text { width } \\
(\mathrm{mm})\end{array}$ & $\begin{array}{c}\text { FZ area } \\
\left(\mathrm{mm}^{2}\right)\end{array}$ & Observation \\
\hline 4 & & 4.24 & 2.00 & 0.37 & 7.32 & Excess penetration \\
\hline 8 & & 4.85 & 2.00 & 0.43 & 8.10 & Full penetration \\
\hline 12 & & 4.37 & 2.00 & 0.46 & 7.46 & Full penetration \\
\hline 16 & & 4.60 & 2.00 & 0.51 & 7.75 & Excess penetration \\
\hline 20 & & 4.90 & 2.00 & 0.56 & 8.30 & Excess penetration \\
\hline
\end{tabular}
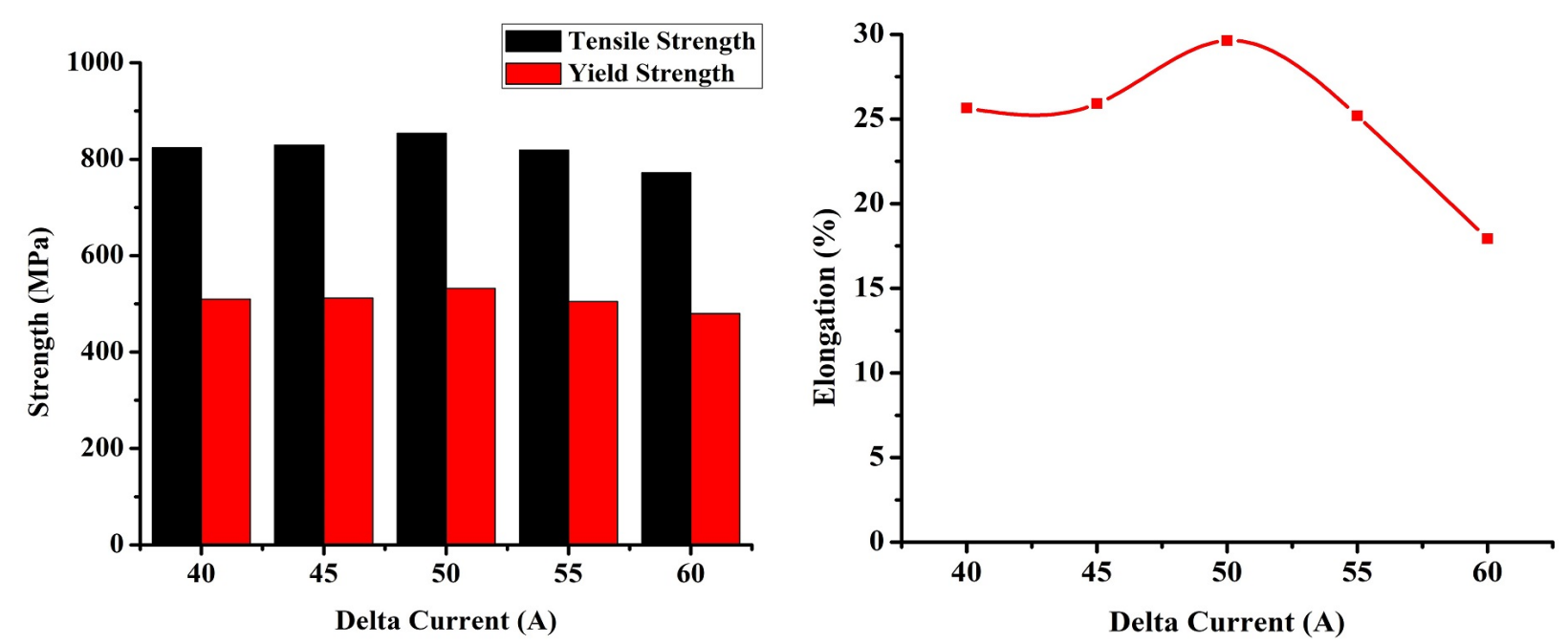

(a) Delta Current (A) vs Strength (MPa)

(b) Delta Current (A) vs Elongation (\%)

Figure 6: Effect of Delta Current on tensile properties of welded joints 
Table 6: Effect of Delta Current on transverse tensile properties of welded joints

\begin{tabular}{cccccc}
\hline $\begin{array}{c}\text { Delta Current } \\
\text { (A) }\end{array}$ & $\begin{array}{c}\text { Tensile strength } \\
\text { (MPa) }\end{array}$ & $\begin{array}{c}\mathbf{0 . 2 \%} \text { Offset yield } \\
\text { strength }(\mathbf{M P a})\end{array}$ & $\begin{array}{c}\text { Elongation in } \mathbf{5 0} \mathbf{~ m m} \\
\text { gauge length (\%) }\end{array}$ & $\begin{array}{c}\text { Joint } \\
\text { efficiency (\%) }\end{array}$ & $\begin{array}{c}\text { Failure } \\
\text { location }\end{array}$ \\
\hline $\mathbf{4 0}$ & 824 & 510 & 25.65 & 94.93 & $\mathrm{FZ}$ \\
$\mathbf{4 5}$ & 829 & 512 & 25.91 & 95.51 & $\mathrm{FZ}$ \\
$\mathbf{5 0}$ & 854 & 532 & 29.64 & 98.39 & $\mathrm{FZ}$ \\
$\mathbf{5 5}$ & 819 & 505 & 25.19 & 94.35 & $\mathrm{FZ}$ \\
$\mathbf{6 0}$ & $\mathbf{7 7 2}$ & 480 & 17.93 & 88.94 & $\mathrm{FZ}$ \\
\hline
\end{tabular}

Table 7: Effect of DCF on transverse tensile properties of welded joints

\begin{tabular}{cccccc}
\hline $\begin{array}{c}\text { Delta Current } \\
\text { Frequency (kHz) }\end{array}$ & $\begin{array}{c}\text { Tensile ctrength } \\
\text { (MPa) }\end{array}$ & $\begin{array}{c}\mathbf{0 . 2 \%} \text { Offset yield } \\
\text { ctrength }(\mathbf{M P a})\end{array}$ & $\begin{array}{c}\text { Elongation in } \mathbf{5 0 ~} \mathbf{~ m m} \\
\text { gauge length (\%) }\end{array}$ & $\begin{array}{c}\text { Joint } \\
\text { efficiency (\%) }\end{array}$ & $\begin{array}{c}\text { Failure } \\
\text { location }\end{array}$ \\
\hline $\mathbf{4}$ & 863 & 548 & 27.93 & 99.42 & $\mathrm{FZ}$ \\
$\mathbf{8}$ & 857 & 534 & 28.72 & 98.73 & $\mathrm{FZ}$ \\
$\mathbf{1 2}$ & 854 & 532 & 29.64 & 98.39 & $\mathrm{FZ}$ \\
$\mathbf{1 6}$ & 838 & 520 & 28.23 & 96.54 & $\mathrm{FZ}$ \\
$\mathbf{2 0}$ & 834 & 517 & 26.22 & 94.35 & $\mathrm{FZ}$ \\
\hline
\end{tabular}

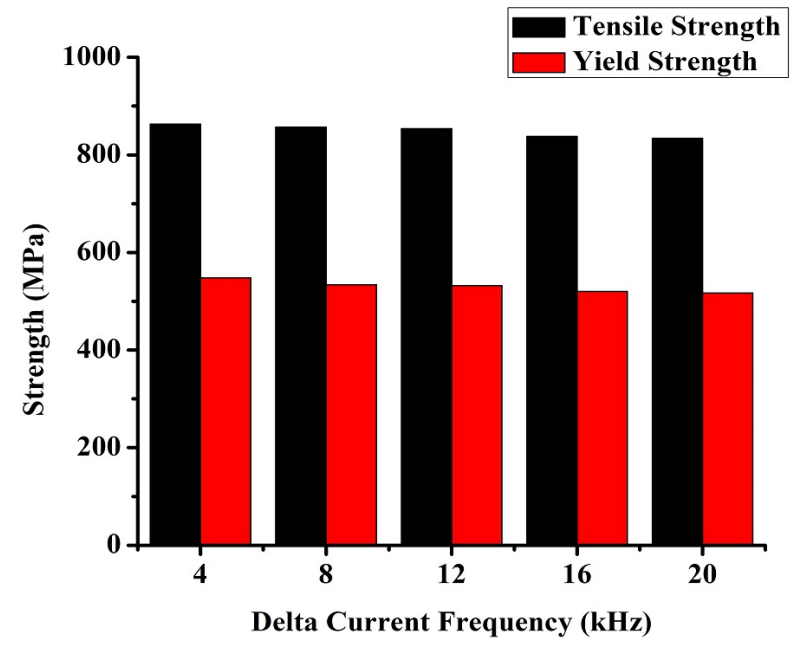

(a) Delta Current (A) vs strength (MPa)

Figure 7: Effect of DCF on tensile properties of welded joints

reduction in ductility of the welded joints as compared to the lower level of $40 \mathrm{~A}$. The joints welded at DC of $50 \mathrm{~A}$ exhibited superior tensile properties. It showed $854 \mathrm{MPa}$ tensile strength, $532 \mathrm{MPa}$ yield strength and $29.64 \%$ ductility. The effect of DCF on the tensile properties of welded joints is shown in Figure 7. The tensile strength decreases with an increase in DCF. The decrease in tensile strength up to $12 \mathrm{kHz}$ is not significant. The higher tensile strength of $863 \mathrm{MPa}$, yield strength of $548 \mathrm{MPa}$, and elongation of $27.93 \%$ was achieved at $4 \mathrm{kHz}$ DCF. The tensile strength decreases from $863 \mathrm{MPa}$ to $834 \mathrm{MPa}$ at a higher level of 20

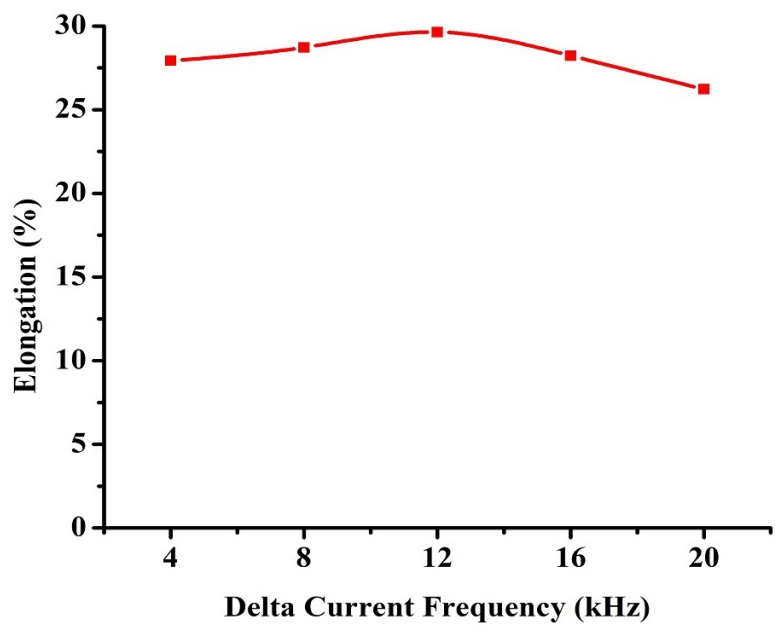

(b) Delta Current (A) vs elongation (\%)

$\mathrm{kHz}$. The tensile elongation increases slightly with an increase in DCF up to $12 \mathrm{kHz}$. Further increase results in a slight reduction in tensile elongation. The tensile elongation is higher about $29.64 \%$ at $12 \mathrm{kHz}$ DCF. The decrease in tensile properties with an increase in DCF is attributed to the accumulation of heat input during welding with increase in each distinct level.

Figure 8 and 9 show the fractographs of the tensile specimens at different levels of DC and DCF. The fracture surface of the base material showed no favorable fracture path and exhibited completely dimpled region. The frac- 


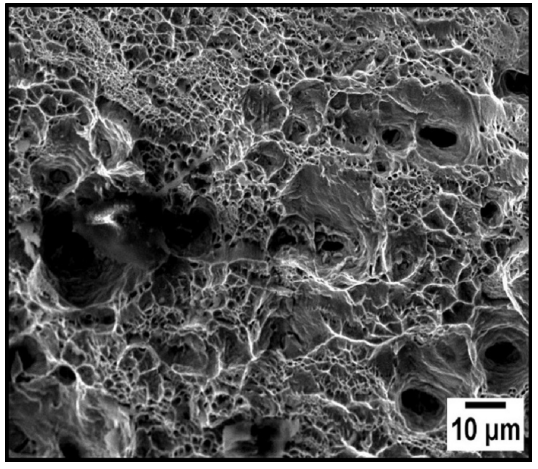

(a) Base metal

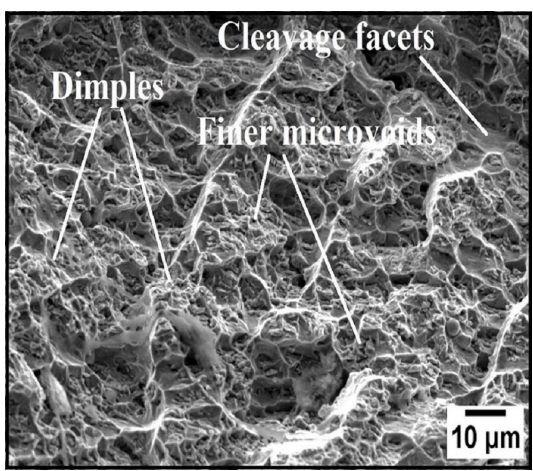

(d) $50 \mathrm{~A}$

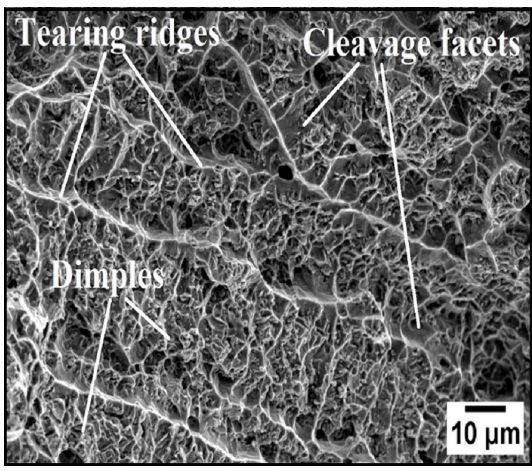

(b) $40 \mathrm{~A}$

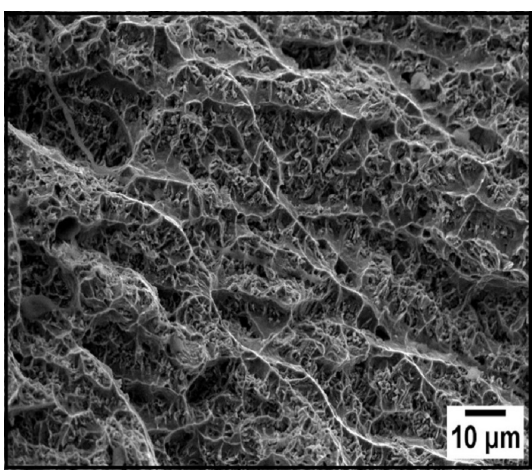

(e) $55 \mathrm{~A}$

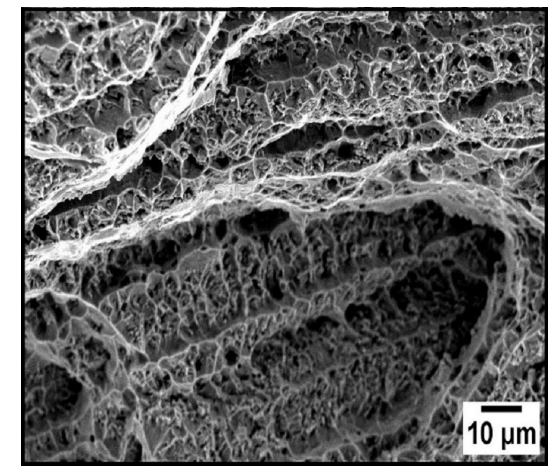

(c) $45 \mathrm{~A}$

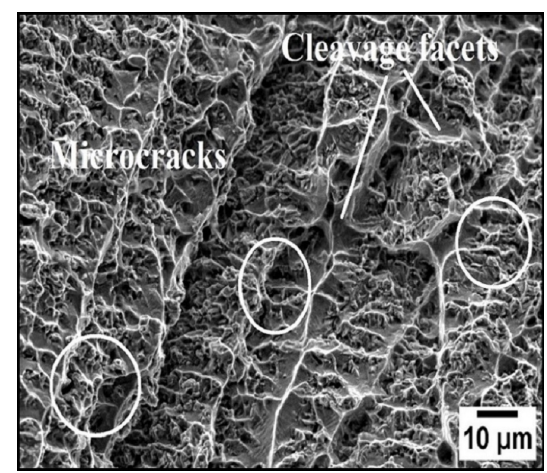

(f) $60 \mathrm{~A}$

Figure 8: SEM fractograph of tensile specimens at different levels of Delta Current

Table 8: Effect of Delta Current on microhardness of various regions

\begin{tabular}{cccc}
\hline $\begin{array}{c}\text { Delta } \\
\text { Current (A) }\end{array}$ & $\begin{array}{c}\text { FZ } \\
\left(\mathbf{H V}_{\mathbf{0 . 5}}\right)\end{array}$ & $\begin{array}{c}\mathbf{H A Z} \\
\left.\mathbf{( H V}_{\mathbf{0 . 5}}\right)\end{array}$ & $\begin{array}{c}\mathbf{B M} \\
\left(\mathbf{H V}_{\mathbf{0 . 5}}\right)\end{array}$ \\
\hline 40 & 261 & 254 & 292 \\
45 & 265 & 258 & 292 \\
50 & 280 & 267 & 292 \\
55 & 260 & 243 & 292 \\
60 & 250 & 235 & 292 \\
\hline
\end{tabular}

Table 9: Effect of DCF on microhardness of various regions

\begin{tabular}{cccc}
\hline $\begin{array}{c}\text { Delta Current } \\
\text { Frequency (kHz) }\end{array}$ & $\begin{array}{c}\mathbf{F Z} \\
\left(\mathbf{H V}_{\mathbf{0 . 5}}\right)\end{array}$ & $\begin{array}{c}\mathbf{H A Z} \\
\left(\mathbf{H V}_{\mathbf{0 . 5}}\right)\end{array}$ & $\begin{array}{c}\mathbf{B M} \\
\left(\mathbf{H V}_{\mathbf{0 . 5}}\right)\end{array}$ \\
\hline 4 & 284 & 273 & 292 \\
8 & 279 & 267 & 292 \\
12 & 280 & 265 & 292 \\
16 & 265 & 260 & 292 \\
20 & 263 & 257 & 292 \\
\hline
\end{tabular}

ture surface of the fusion zone showed a dendritic pattern and exhibited a favorable fracture path. The fracture oc- curred along the interdendritic regions. The joints welded using DC up to $50 \mathrm{~A}$ and DCF up to $12 \mathrm{kHz}$ showed finer and deeper dimples, whereas it was observed to be coarser and shallower at a higher level of $60 \mathrm{~A} \mathrm{DC}$ and $20 \mathrm{kHz}$ DCF.

\subsection{Microhardness}

The microhardness of various regions of the welded joints under incremental levels of DC and DCF are compiled in Tables 8 and 9. It shows that the fusion zone hardness is lower than the base material. It is attributed to the depletion of strengthening alloying elements from the dendrite core into the interdendritic regions which leads to the formation of intermetallic laves phase. The hardness of the fusion zone is dependent on the $\mathrm{Nb}$ content in the dendrite core regions. Higher the depletion of $\mathrm{Nb}$ from the dendrite core regions, lower the hardness of the fusion zone. Figure $10 \mathrm{a}$ ) and b) shows the microhardness distribution of welded joints across the mid-thickness region at different levels of DC and DCF. It showed microhardness gradient i.e. variation in microhardness of the fusion zone from the weld centre. The microhardness gradient shows the uniformity of the elemental composition in the weld microstruc- 


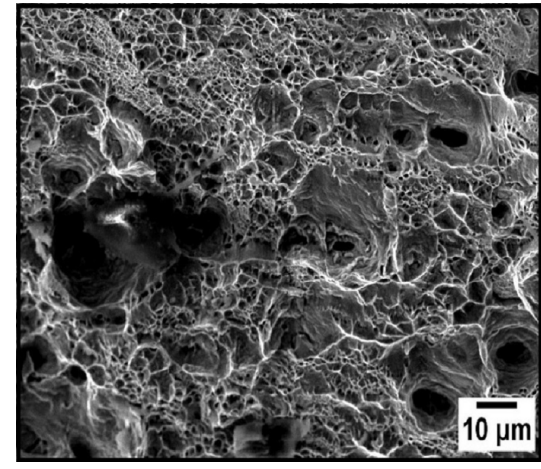

(a) Base metal

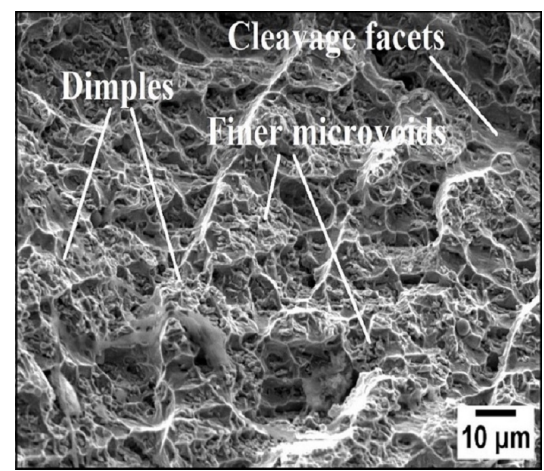

(d) $12 \mathrm{kHz}$

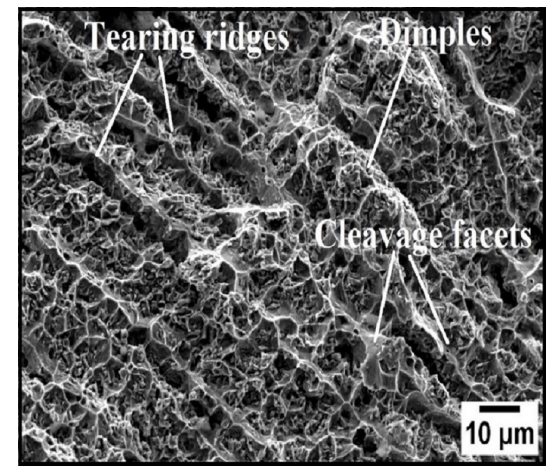

(b) $4 \mathrm{kHz}$

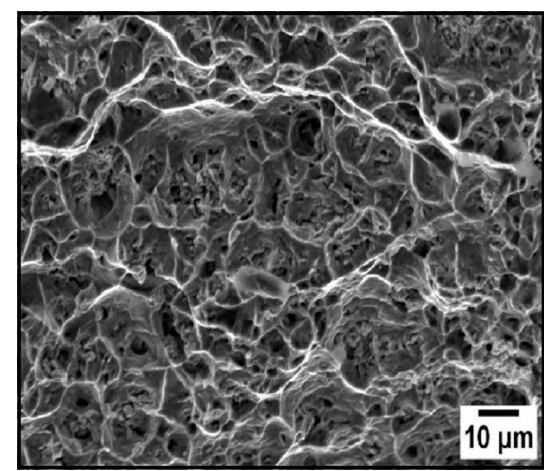

(e) $16 \mathrm{kHz}$

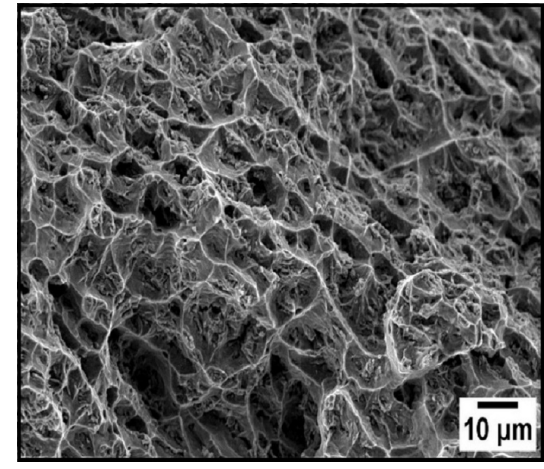

(c) $8 \mathrm{kHz}$

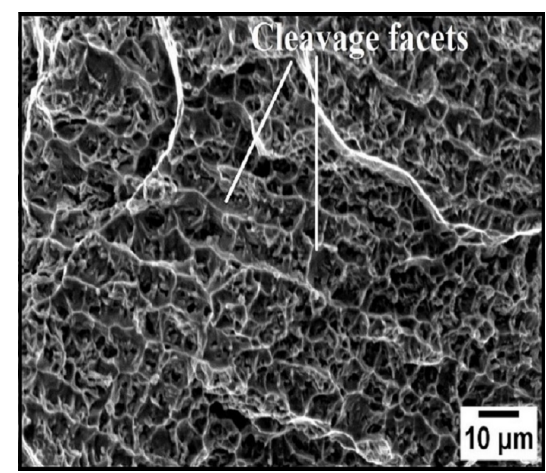

(f) $20 \mathrm{kHz}$

Figure 9: SEM fractograph of tensile specimens at different levels of DCF
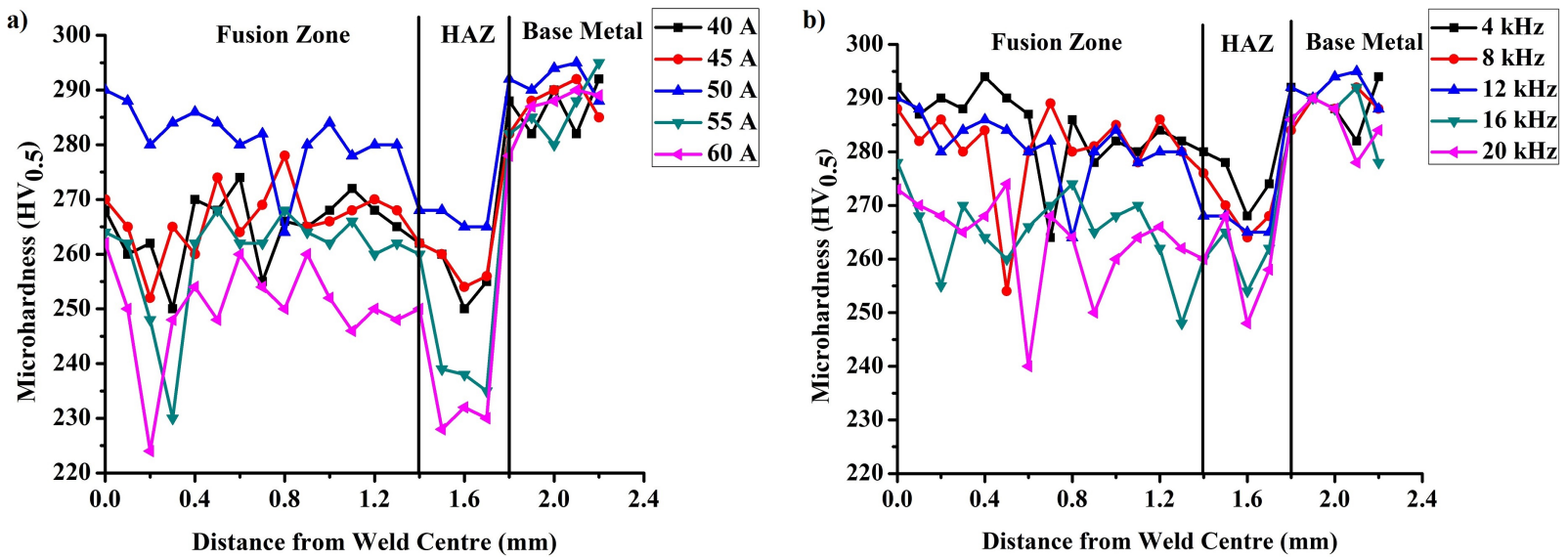

Figure 10: Microhardness variationacross the welded joint along the mid-thickness region at different levels of a) DC and b) DCF

ture. The joints welded at $50 \mathrm{~A} \mathrm{DC}$ and up to $12 \mathrm{kHz}$ DCF showed a comparatively reduced microhardness gradient as compared to the higher levels of DC and DCF. However, lower microhardness values were observed in the fusion zone. These are the regions which are mainly responsible for the failure of the welded joints in the fusion zone. The microhardness gradient in the fusion zone is higher at incremental levels of DC and DCF. It is attributed to the higher heat input. Figure 11a) and b) shows the effect of DC and DCF on average microhardness of the fusion zone (FZ) and heat affected zone (HAZ). It follows the trend of tensile strength at incremental levels of DC and DCF. 

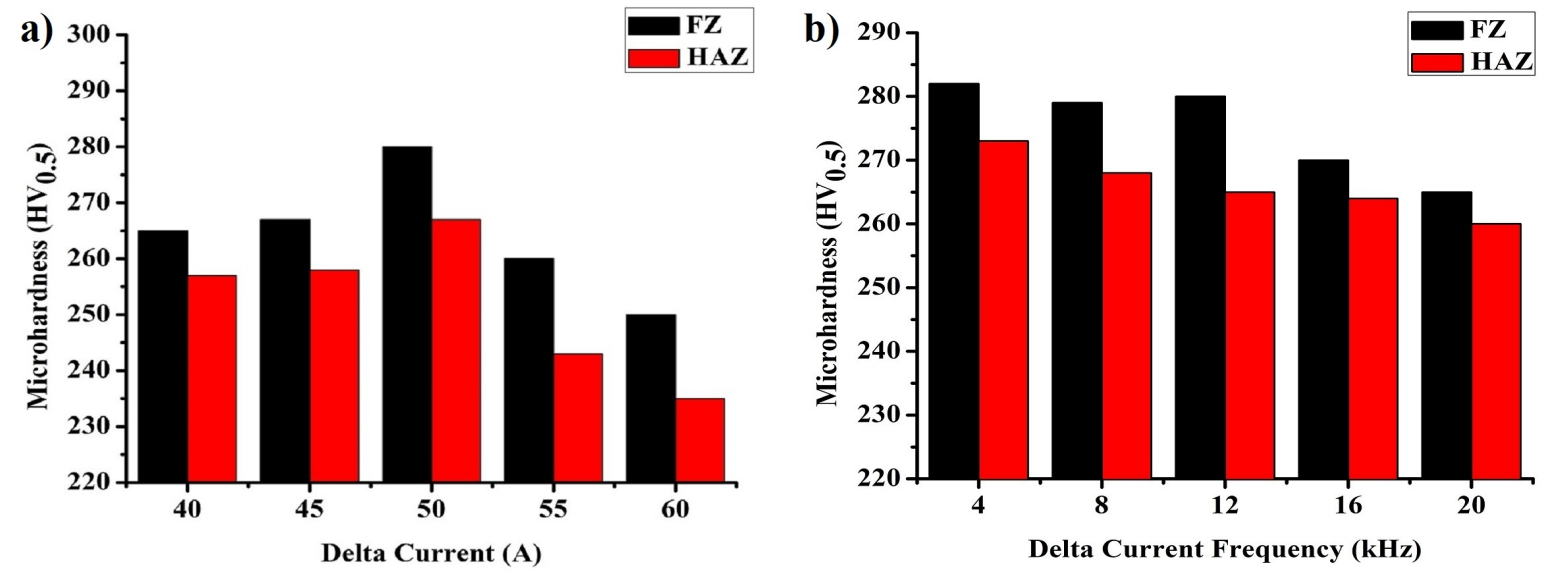

Figure 11: Effect of a) DC and b) DCF on average microhardness of FZ and HAZ
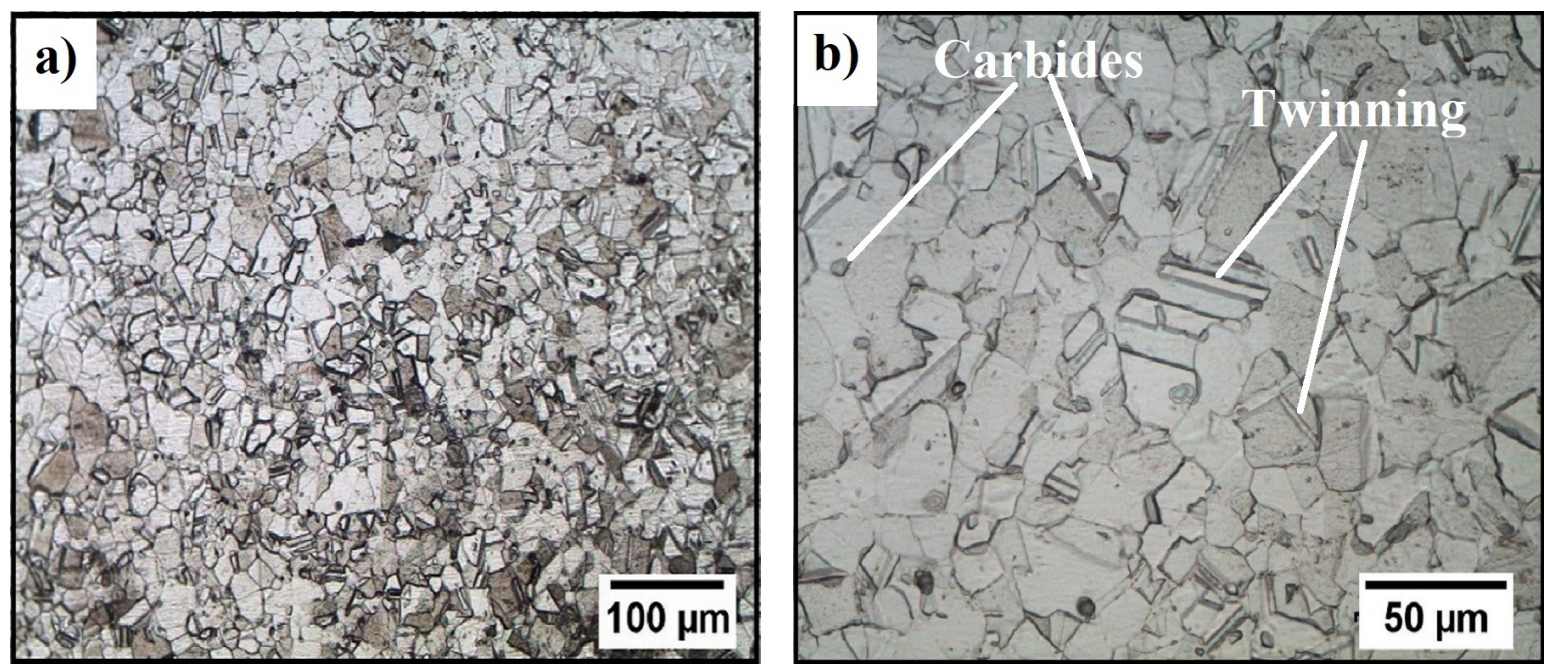

Figure 12: Optical microstructure of base material in $980^{\circ} \mathrm{C}$ solution treated condition: a) lower magnification (200X) b) higher magnification (500X)

\subsection{Microstructure}

The base material microstructure of Inconel 718 alloy in $980^{\circ} \mathrm{C}$ solution treated condition is shown in Figure 12. It shows an equiaxed grain structure in nickel austenitic matrix with the presence of carbides at the grain boundaries and across the grains. The annealing twinning is clearly observed in grains. Figure 13 shows the effect of DC on the microstructure of fusion zone (FZ). The dendritic structure of the fusion zone gets coarsen with the increase in DC compared to lower level and higher level of DC. The increase in DC from a lower level of $40 \mathrm{~A}$ to mid-level of 50 $\mathrm{A}$, showed refinement in the dendritic structure of the fusion zone. However, further increase in DC results in the coarsening of dendrites. The dendritic structure is much coarser at a higher level of $60 \mathrm{~A}$. It shows larger interden- dritic spacings which are preferential sites for segregation of alloying elements.

Figure 14 shows the microstructure of the fusion zone at incremental levels of DCF. The fusion zone of the joints welded at $4 \mathrm{kHz}$ DCF shows finer dendritic structure as compared to the other levels. The refinement in the fusion zone is observed up to $12 \mathrm{kHz}$. Further increase results in the coarsening of the dendrites. The fusion zone at a higher level of DCF $(20 \mathrm{kHz})$ shows coarser dendritic structure. This clearly infers that the average heat input rises during welding. 


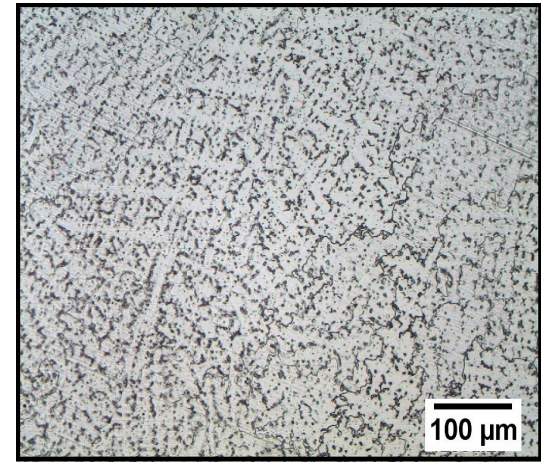

(a) $40 \mathrm{~A}$

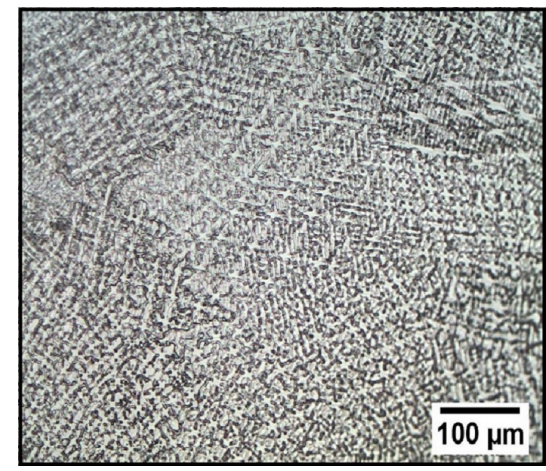

(b) $45 \mathrm{~A}$

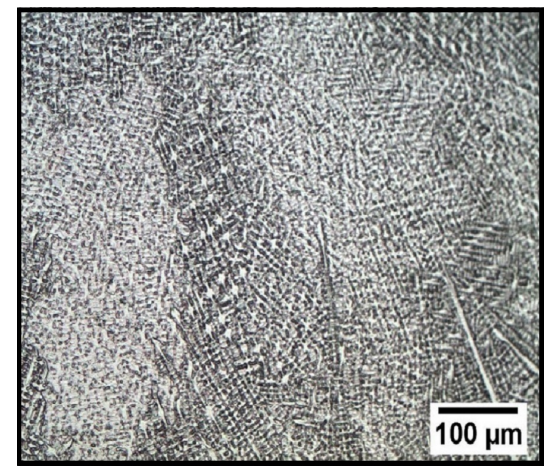

(c) $50 \mathrm{~A}$

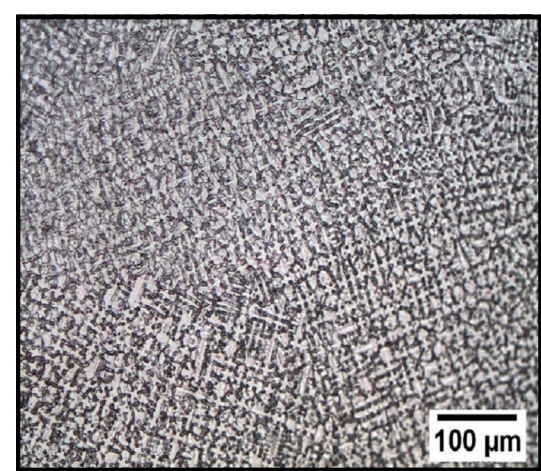

(d) $55 \mathrm{~A}$

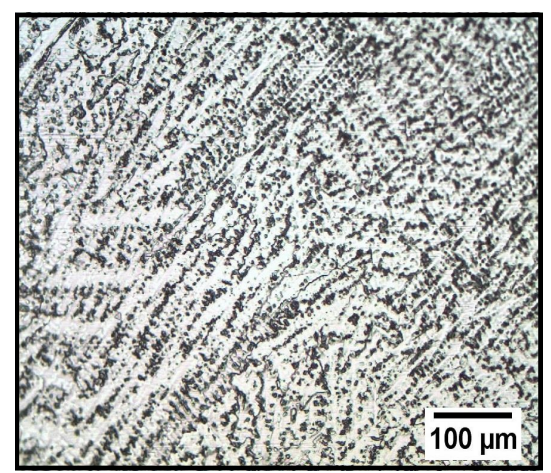

(e) $60 \mathrm{~A}$

Figure 13: Effect of Delta Current on fusion zone (FZ) microstructure

\section{Discussion}

\subsection{Effect of DC and DCF on macrostructure}

Gas tungsten constricted arc (GTCA) welding is the advanced variant of GTAW process in which the welding arc is constricted by the magnetic field produced by DC pulsing at a very high frequency up to $20 \mathrm{kHz}$. As DC increases, there is an increase in average heat input during welding at incremental levels due to the constant welding speed. When DC increases, the magnetic field increases resulting in increase in magnetic arc constriction. The magnetic arc constriction reduces the wastage of heat on the outer flare and causes localized heating of the metal at the joint. This results in increase in heat intensity of the arc and less time is required for the melting of the metal at the joint. So, the interaction effect exists between the $\mathrm{DC}$ and welding speed. The increase in DC must be associated with increase in welding speed. When the DC increased from lower level of $40 \mathrm{~A}$ to mid-level of $50 \mathrm{~A}$, the fusion zone area decreased. It is attributed to the increase in magnetic arc constriction. Further increase in DC above $50 \mathrm{~A}$ resulted in increased weld bead geometry. It is attributed to the increase in heat input effect. In this investigation, to study the main effect of DC, the interaction effect of welding speed with DC is neglected i.e. welding speed is kept constant. Increase in magnetic arc constriction with incremental levels of DC at constant welding speed results in more melting of the metal at the joint. The benefits of the magnetic arc constriction are not achieved at higher level of DC due to the increased heat input effect and constant welding speed.

The increase in DCF results in an increase in weld bead geometry. It is not significant up to $12 \mathrm{kHz}$. However, it is more pronounced at a higher level of DCF $(20 \mathrm{kHz})$. It is attributed to the increase in average heat input during welding. As DCF increases the distance between the two consecutive peaks of the $\mathrm{DC}$ decreases. This results in reduced rise time and fall time which in turn results in much faster magnetic arc constriction and release. Thus, less time is available for the weld pool to transfer heat to the adjacent regions during welding in each welding thermal cycle. The end effect is that it results in the piling of heat input during welding in each welding thermal cycle. The piling of heat input increases with incremental levels of DCF. It is the main reason that the $\mathrm{DC}$ pulsing benefits are not observed at higher levels. As the DC and DCF showed a sig- 


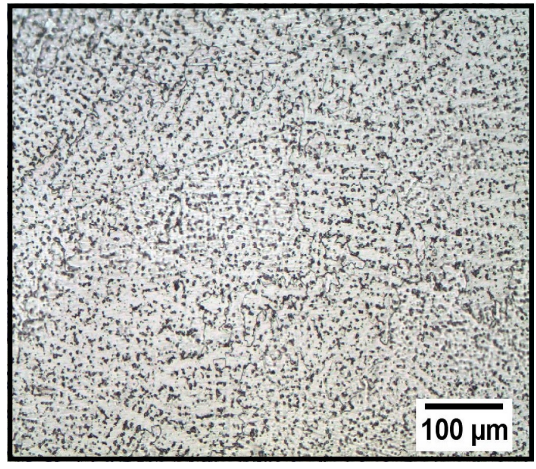

(a) $4 \mathrm{kHz}$

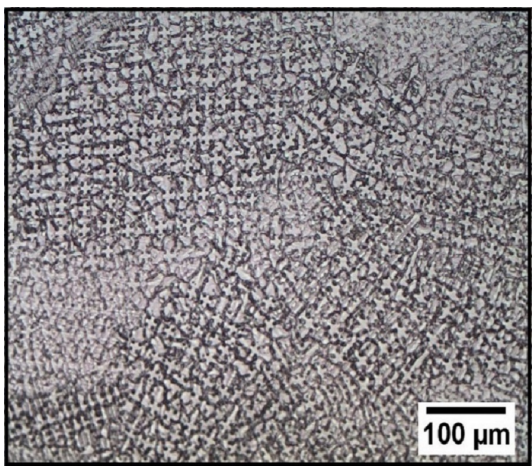

(b) $8 \mathrm{kHz}$

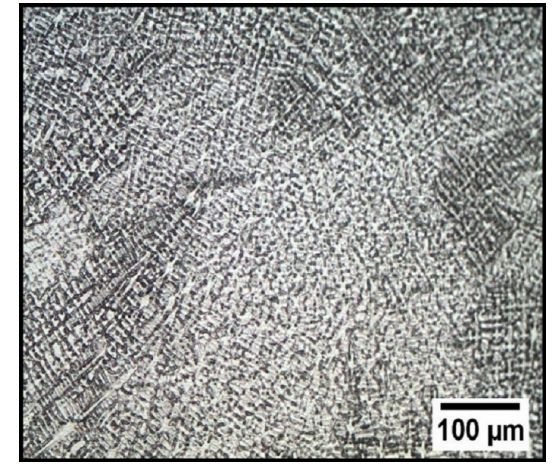

(c) $12 \mathrm{kHz}$

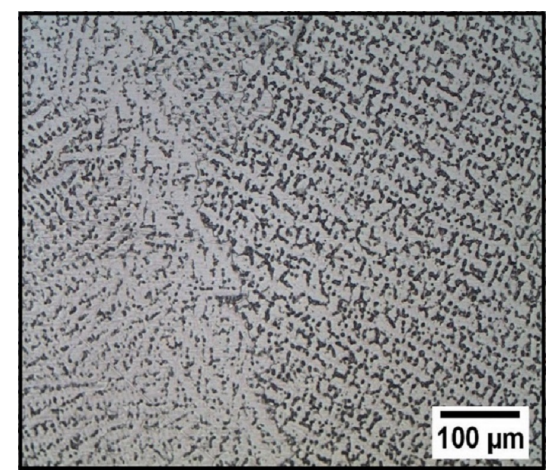

(d) $16 \mathrm{kHz}$

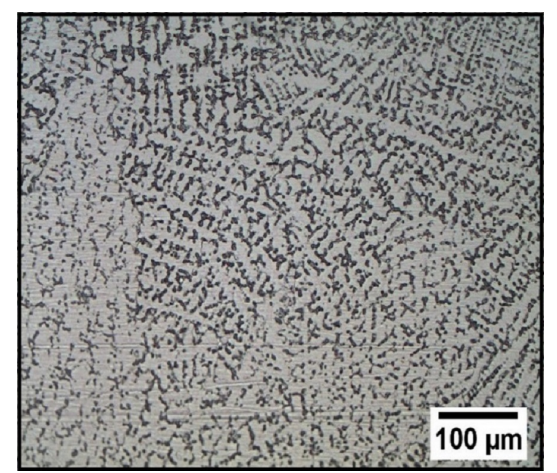

(e) $20 \mathrm{kHz}$

Figure 14: Effect of DCF on fusion zone (FZ) microstructure

nificant effect on the weld bead control, the optimum selection of the weld bead is important.

\subsection{Effect of DC and DCF on tensile properties}

The tensile properties of Inconel 718 alloy joints aremainly controlled by the heat input, welding techniques, and elemental composition. $\mathrm{Nb}$ is the alloying element which is mainly used for high temperature strengthening. But the main problem is, it is having a high partition coefficient [28]. It results in the segregation of $\mathrm{Nb}$ in interdendritic regions. The tensile failure was observed in the fusion zone of all the joints due to the presence of laves phase in the fusion zone due to the segregation of alloying elements. As segregation is a time-dependent phenomenon, the weld cooling rate and heat input is major factor in controlling the microsegregation and subsequent formation of Laves phase in the weld $[29,30]$.

As DC increases the average heat input during welding decreases. This results in an increase in the cooling rate. The increase in the cooling rate provides less time for the growth of the dendrites and solute redistribution. This causes refinement in the fusion zone. As the dendritic structure becomes finer, the interdendritic spacing reduces which are the preferential sites for segregation of alloying elements and laves phase formation. Thus, the magnetic arc constriction reduces the depletion of alloying elements from the matrix and core of dendrites to interdendritic regions. The reduced segregation effect provides better strength properties. The increase in tensile strength from a lower level of $40 \mathrm{~A}$ to mid-level of $50 \mathrm{~A}$ is attributed to the refinement in the dendritic structure of fusion zone. However, the tensile properties decrease significantly above $50 \mathrm{~A}$. The benefits of magnetic arc constriction with the increase in DC at a constant welding speed are not obtained at a higher level of $60 \mathrm{~A}$ due to the fact that the heat input effect is becoming more dominant, which reduces the cooling rate. It provides enough time for the growth of the dendrites and solute redistribution. This results in increase in the interdendritic spacing with more segregation of alloying elements. The depletion of alloying elements from the matrix and the core of the dendrites in interdendritic regions reduces the strength of the welded joints [15-17]. Thus, the reduced tensile proper- 
ties at a higher level of DC is attributed to the coarser dendritic structure. Increase in DCF resulted in a decrease in tensile properties of the welded joints. It is attributed to the coarsening of the dendrites. As there is an increase in the stacking of average heat input during welding in welding thermal cycles with incremental levels of DCF, the cooling rate decrease and coarsening of the dendritic structure occurs. Also, the magnitude of thermal oscillation and agitation is reduced with incremental levels. This effect is more significant above $12 \mathrm{kHz}$ showing significant reduction in tensile properties. Laves phase being a brittle intermetallic compound provides favorable sites for easy crack initiation and propagation [26, 27]. Bae et al. [31] observed that the brittle microcracks were initiated from the laves particles and causes reduction in the microplastic zone ahead of the crack tip leading to the rapid crack propagation.

\subsection{Effect of DC and DCF on microhardness}

The microhardness survey showed variation in the microhardness of the fusion zone from the weld centre. The significant variation in microhardness is allocated to the segregation effect. The alloying elements which have a higher partition coefficient are more pronounced for segregation in interdendritic regions [18]. The strengthening alloying elements get depleted from the matrix and segregate in the interdendritic regions for laves phase formation. This results in lowering the microhardness at some points in the fusion zone from the weld centre.

The increase in DC from a lower level of $40 \mathrm{~A}$ to midlevel of $50 \mathrm{~A}$ results in increase in average microhardness of fusion zone. It is attributed to the refinement in the fusion zone due to the decrease in heat input and increase in cooling rate. Refinement in fusion zone results in decrease in interdendritic spacing which are preferential sites for the segregation of alloying elements. Thus, the refinement of the fusion zone microstructure reduces the depletion of the alloying elements from the matrix in the interdendritic region and increases the average microhardness value of the fusion zone. Further increase in DC above 50 A resulted in a decrease in average microhardness of fusion zone. It is attributed to the coarsening of the fusion zone microstructure and larger extent of segregation of alloying elements for lave phase formation. The incremental level of DCF results in a decrease in the average microhardness values of FZ. It is attributed to the coarsening of the fusion zone microstructure due to the increase in stacking of average heat input during welding which results in increased segregation effect and depletion of strengthening elements from the matrix. The grain growth in HAZ leads to the reduced hardness in HAZ as compared to the base metal and fusion zone. Though the HAZ hardness is lower than base metal and fusion zone, failure resulted in the fusion zone of the joints only. It is attributed to the segregation of $\mathrm{Nb}$ leading to the laves phase formation in weld metal region. Ram et al. [9] stated that laves phase does not provide plastic deformation along with the matrix and provides easy crack initiation and propagation. Furthermore, it depletes the strengthening alloying elements from the matrix which provides the region of lower hardness in the fusion zone which are mainly responsible for the failure of the joints in fusion zone only.

\subsection{Effect of DC and DCF on microstructure}

Inconel 718 alloy is a heavily alloyed material with a large solidification range up to $150^{\circ} \mathrm{C}$. It solidifies in the dendritic mode by constitutional supercooling and the growth of the dendrites is dependent on the heat input and cooling rate $[15,17]$. Increase in DC from a lower level of $40 \mathrm{~A}$ to mid-level of 50 A showed refinement in the dendritic structure of fusion zone. Because the increase in DC increases magnetic arc constriction which reduces the effect of average heat input during welding and enhances the cooling rate. The magnetic arc constriction causes localized melting of metal at the joint and reduces average heat input during welding. This increases the cooling rate and reduces the thermal gradient towards the weld centre and base metal. The degree of undercooling in the solidifying weld pool is inversely proportional to the ratio of thermal gradient and growth rate $[26,27]$. Thus, the thermal gradient towards the weld centre and base metal reduces. It results in significant undercooling which leads to the refinement of the dendritic structure of the fusion zone. The finer dendritic structure observed in $50 \mathrm{~A} \mathrm{DC}$ is attributed to the increased magnetic arc constriction and optimum interaction effect of DC and welding speed. The magnetic arc constriction and release also enhance the cooling rate by increasing the fluid motion in the weld pool. This provides an increase in the nucleation sites and refinement in the fusion zone. However, the benefits of magnetic arc constriction were not achieved at a higher level due to the significant heat input effect. The increase in DC at the constant welding speed increases the average heat input during welding. The heat input effect is more severe at a higher level of DC due to the constant welding speed. As the magnetic arc constriction increases the heat intensity of the arc, it reduces the time required for the melting of the metal at the joint. Since the welding speed is kept constant to understand the main effect of DC, there is more melting of 
metal at the joint at incremental levels of DC. The significant coarsening of a dendritic structure is observed at a higher level of $60 \mathrm{~A}$.

The results showed an increase in the growth of the dendrites and interdendritic regions with incremental levels of DCF. This clearly indicates that the average heat input increases with increase in DCF. As the DCF increases the distance between the two adjacent peaks of the DC decreases, which reduces the time for the heat to transfer in the next welding cycle. Thus, there is a piling of heat input in each welding cycle. The end effect is an increase in average heat input during welding with incremental levels of DCF. The piling of heat input increases the thermal gradient between the weld pool and the base metal. Thus, there is enough time for the heat transfer due to the reduced cooling rate. This provides the preferential conditions for the growth of the dendrites. The coarsening of the fusion zone dendritic structure is mainly responsible for the reduction in mechanical properties of the welded joints at $20 \mathrm{kHz}$. The increase in growth of the dendrites is not significant up to $12 \mathrm{kHz}$. This is the reason that there is no notable reduction in mechanical properties up to $12 \mathrm{kHz}$. The welded joints showed higher mechanical properties at a lower level due to the significant refinement in the dendritic structure of the fusion zone. It is attributed to the optimum heat input and thermal oscillation of the weld pool. The DC pulsing causes thermal oscillation of the molten pool which causes an interruption in the weld pool solidification. It disturbs solidification process and the growth of the dendrites resulting in fragmentation of the dendrites. The broken dendrites also act as nuclei for refinement in the fusion zone during solidification. The beneficial effects are observed up to $12 \mathrm{kHz}$. At a higher level of DCF, the piling of heat input in weld thermal cycle causes the melting of newly forming nuclei and restricts refinement in the fusion zone.

\section{Conclusions}

1. Delta Current (DC) is observed to have significant effect on the tensile properties and microstructural characteristics of Inconel 718 alloy welds compared to the Delta Current Frequency.

2. Increase in DC from lower level of $40 \mathrm{~A}$ to $50 \mathrm{~A}$ results in increase in tensile properties and microhardness of the welded joints. It is attributed to the refinement in dendritic structure of fusion zone. Further increase results in decrease in mechanical proper- ties due to the coarsening of dendritic structure of fusion zone.

3. Increase in Delta Current Frequency (DCF) from lower level of $4 \mathrm{kHz}$ to higher level of $20 \mathrm{kHz}$ results in decrease in the mechanical properties of the welded joints. It is attributed to the coarsening of dendritic structure due to the piling of average heat input during welding.

4. The joints welded at DC of $50 \mathrm{~A}$ and DCF of $4 \mathrm{kHz}$ exhibited superior tensile properties. Thus, the selection of DC and DCF at optimum level is important for grain refinement in the fusion zone and to attain superior tensile properties in welded joints.

5. The GTCA welded Inconel 718 alloy joints made using optimized DC and DCF showed joint efficiency of $99.20 \%$ and an elongation of $27.93 \%$. These tensile properties are comparatively much higher than the joints made using constant current, pulsed current and magnetic arc oscillation techniques of GTAW process.

Acknowledgement: The authors express their sincere gratitude to the Director, Vikram Sarabhai Space Centre (VSSC), ISRO, Thiruvananthapuram, Kerala for providing the financial support and base material to carry out this investigation through ISRO RESPOND scheme(Project No. ISRO/RES/3/728/16-17).

\section{References}

[1] Gordine J., Welding of Inconel 718, Weld Res. Suppl., 1970, 531537.

[2] Lund C.H., Physical Metallurgy of Nickel Base Superalloys, Defence Metals Information Centre (DMIC) Report 153, Battelle Memorial Institute, Ohio, 1961.

[3] Wagner H. J., Hall A., Physical Metallurgy of Alloy 718, Defence Metals Information Centre (DMIC), Report 217, Battle Memorial Institute Columbus, Ohio, 1965.

[4] Lippold J., DuPont J.C., DuPont J.N., Kiser S.D., Welding Metallurgy and Weldability of Nickel Base Alloys, John Wiley and Sons, Inc., New Jersey, 2009.

[5] Agilan M., Krishna Chenna S., Manwatkar Sushant K., Vinayan E.G., Sivakumar D., Bhanu Pant, Effect of Welding Processes (GTAW \& EBW) and Solutionizing Temperature on Microfissuring Tendency in Inconel 718 Welds, Mater. Sci. For., 2004, 710, 603607.

[6] Hari Krishna E., Prasad K., Singh V., Kumar V., A comparative evaluation of low cycle fatigue behavior of conventional and modified INCONEL 718, Trans. Ind. Inst. Met., 2010, 63, 515-516.

[7] Hari Krishna E., Prasad, K., Singh, V., Kumar, V., Fatigue Crack Growth Behaviour of Conventional and Modified IN 718 Superalloys at $650{ }^{\circ} \mathrm{C}$, Trans. Ind. Inst. Met., 2012, 66, 1-4. 
[8] Radhakrishna C.H., Rao K.P., The formation and control of Laves phase in superalloy 718 welds, J. Mater. Sci., 1997, 32, 1977-1984.

[9] Ram G.D.J., Reddy A.V., Rao K.P., Reddy G.M., Control of Laves phase in Inconel 718 GTA welds with current pulsing, Sci. Tech. Weld. Join, 2004, 9, 390-398.

[10] Sivaprasad K., Raman S.G.S., Mastanaiah P., Reddy G.M., Influence of magnetic arc oscillation and current pulsing on microstructure and high temperature tensile strength of alloy 718 TIG weldments, Mater. Sci. Engg. A, 2006, 428, 327-331.

[11] Manikandan S.G.K., Sivakumar D., Rao K.P., Kamaraj M., Microstructural characterization of liquid nitrogen cooled Alloy 718 fusion zone, J Mater. Proc. Tech., 2014, 214, 3141-3149.

[12] Rao S.G., Saravanan K., Harikrishnan G., Sharma V.M.J., Ramesh Narayan P., Sreekumar K., Sinha P., Local Deformation Behaviour of Inconel $718 \mathrm{TIG}$ weldments at Room Temperature and $550^{\circ} \mathrm{C}$, Mater. Sci. For., 2012, 710, 439-444.

[13] Cortés R., Barragán E.R., López V.H., Ambriz R.R., Jaramillo D. Mechanical properties of Inconel 718 welds performed by gas tungsten arc welding, Int. J. Adv. Mfg. Tech., 2017, 94, 3949-3961.

[14] Rodríguez N.K., Barragán E.R., Lijanova I.V., Cortés R., Ambriz R.R., Méndez C., Jaramillo D., Heat Input Effect on the Mechanical Properties of Inconel 718 Gas Tungsten Arc Welds, Proceedings of the 17th International Conference on New Trends in Fatigue and Fracture, 2017, 255-262.

[15] Reddy G.M., Murthy C.V.S., Viswanathan N., Rao K.P., Effects of electron beam oscillation techniques on solidification behaviour and stress rupture properties of Inconel 718 welds, Sci. Tech. Weld. Join., 2007, 12, 106-114.

[16] Sundararaman M., Potdar P.J., Microstructural investigations of Electron Beam Welded Alloy 718, Superalloys 718, 625, 706 and Derivatives, Edited by E.A. Loria TMS, 2005, 477-486.

[17] Ram G.D.J., Reddy A.V., Rao K.P., Reddy G.M., Sarin Sundar J., Microstructure and Tensile properties of Inconel 718 pulsed NdYag Laser Welds, J. Mater. Proc. Tech., 2005, 167, 73-82.

[18] Odabasi A., Unlu N., Goller G., Eruslu M.N., A Study on Laser Beam Welding (LBW) Technique: Effect of Heat Input on the Microstructural Evolution of Superalloy Inconel 718, Metall. Mater. Trans. A, 2010, 41, 2357-2365.

[19] Ram G.D.J., Reddy A.V., Rao K.P., Reddy G.M., Improvement in stress rupture properties of Inconel 718 gas tungsten arc welds using current pulsing, J. Mater. Sci., 2005, 40, 1497-1500.
[20] Manikandan S.G.K., Sivakumar D., Rao K.P., Kamaraj M., Control of Laves phase in Inconel 718 weldments, Mater. Sci. For., 2012, 710, 614-619.

[21] Anbarasan N., Jerome S., Suresh G., Oyyaravelu R., Effect of Pulse Frequency on Microstructural and Corrosion Properties of Inconel 718 Gas Tungsten Arc Weldments, Trans. Ind. Met., 2019, 72, 1299-1311.

[22] Ram G.D.J., Rao A.V., Rao K.P., Reddy G.M., Rao A.S., Effect of magnetic arc oscillation on microstructure and properties of Inconel 718 GTA welds, Trans. Ind. Inst. Met., 2009, 59, 85-97.

[23] Sivaprasad K., Raman S.G.S., Influence of magnetic arc oscillation and current pulsing on fatigue behavior of alloy 718 TIG weldments, Mater. Sci. Eng. A, 2007, 448, 120-127.

[24] Anbarasan N., Narein N., Jerome S., Influence of Mechanical Arc Oscillation on the Microstructural and Mechanical Properties of Inconel 718 Welds, Trans. Ind. Inst. Met., 2019, 72, 1541-1544.

[25] Bansal A., Sharma A.K., Das S., Kumar P., Characterization of microstructure and strength of microwave welded Inconel 718 joints at $2.45 \mathrm{GHz}$ frequency, Kov. Mater., 2016, 54, 27-35.

[26] Ram G.D.J., Reddy A.V., Rao, K.P., Reddy G.M., Microstructure and mechanical properties of Inconel 718 electron beam welds, Mater. Sci. Tech., 2005, 21, 1132-1138.

[27] Reddy G.M., Murthy C.V.S., Rao K.S., Rao K.P., Improvement of mechanical properties of Inconel 718 electron beam weldsinfluence of welding techniques and post weld heat treatment, Inter. J. Adv. Mfg. Tech., 2008, 43, 671-680.

[28] Radhakrishna C.H., Rao K.P., Srinivas S., Laves phase in superalloy 718 weld metals, J. Mater. Sci. Let., 1995, 14, 1810-1812.

[29] Sivaprasad K., Raman S.G.S., Influence of Weld Cooling Rate on Microstructure and Mechanical Properties of Alloy 718 Weldments, Metall. Mater. Trans. A, 2008, 39, 2115-2127.

[30] Manikandan S.G.K., Sivakumar D., Rao K.P., Kamaraj M., Effect of weld cooling rate on Laves phase formation in Inconel 718 fusion zone, J. Mater. Proc. Tech., 2014, 214, 358-364.

[31] Bae S.H., Kwon S.I., Yoon J.G., Lee J.H., Do J.H., Kim I.S., Hong H.U. Effect of Post Weld Heat Treatment on Cryogenic Mechanical Properties of Electron Beam Welded Cast Inconel 718, Metall. Mater. Trans. A, 2013, 45, 537-542. 